\title{
What Is 'Early Intervention' for Work Related Difficulties for People with Multiple Sclerosis? A Case Study Report
}

Joanna Sweetland", Diane E Playford, Kathryn A Radford

*Corresponding author: Joanna Sweetland, Research Occupational Therapist, UCL Institute of Neurology, Queen Square, London, WC1N 3BG, UK; E-mail: J.sweetland@ion.ucl.ac.uk

Received date: Oct 07, 2014, Accepted date: Nov 25, 2014, Published date: Nov 30, 2014

Copyright: ( 2014 Joanna S, et al. This is an open-access article distributed under the terms of the Creative Commons Attribution License, which permits unrestricted use, distribution, and reproduction in any medium, provided the original author and source are credited.

\begin{abstract}
Background: Employment matters and at diagnosis most people with multiple sclerosis are in full time work or education. $75 \%$ of people with multiple sclerosis report the condition has impacted on this employment or career opportunities. Early intervention to support people in work is advocated for in the literature. This paper starts the journey of exploring what is meant by early.

Methods: A randomized control trial was undertaken offering either occupational therapy led early intervention or usual care to people diagnosed with multiple sclerosis within one year. Two cases were purposively selected from the treatment group and used to illustrate the importance as well as the nature of early intervention.

Results: Both participants received occupational therapy led support which included fatigue management, advice about legal rights, support accessing services such as Access to Work, and support with disclosure in the workplace.

Conclusions: Neither of the participants had reported any work problems at the point of referral. However the clinical intervention led to the identification of small concerns and worries. The education and support offered to these two participants alleviated these worries. Early support and education to enable people with multiple sclerosis to manage their condition in the work place can have a positive impact. This may equip them better for the journey ahead.
\end{abstract}

Keywords: Multiple sclerosis; Vocational rehabilitation; Case study

\section{Introduction}

Approximately 100,000 people in the UK have a diagnosis of Multiple Sclerosis [1](MS) and 2.5 million people worldwide [2]. MS is the most common neurological condition among young adults diagnosed usually between the ages of 20-24 [3]. This is at a stage in life when people are starting their journey in the world of employment, a time of seeking independence and financial security through work as well as social identity. Being diagnosed with MS produces a myriad of challenges not least of which is 'can one continue to work?'

Employment matters [4]. Not only is work good for health, for income and for social status, but also for relationships. It is a cornerstone of independent living and for many people, central to their identity [5]. Black [6] argues that work is good for health, a belief supported by evidence extoling the positive impact on physical and mental health and well-being [7]. A recent evaluation of Vocational Rehabilitation (VR) services to support people with cancer takes this further arguing that 'good work' is good for health [8].

VR is defined as whatever helps someone with a health problem return to, and remain in, work [9]. It involves helping people find work, helping those who are in work but having difficulty and supporting career progression in spite of illness or disability [10,11]. Supporting people with long term neurological condition to regain and remain in work is a quality requirement of the National Service Framework [12] and a remit of UK health services to ensure that people with long term conditions remain in work [13]. Despite this there is strong evidence to show that people with MS (pwMS) experience a premature exit from the workforce [14].

At diagnosis most pwMS are in full-time work or education [15]. But as the condition progresses the number of pwMS remaining in work decreases and within 20 years of onset only $<22 \%$ remain in employment [16-18]. A striking finding from the Multiple Sclerosis International Federation Survey on MS and Employment was that almost half of the people leaving the workforce did so within three years of diagnosis [14]. Studies from around the world have reported a high incidence of unemployment and job loss even in people with mild MS [14]. A Work Foundation report found 37\% may be compelled to change or quit their jobs due to fluctuating functional capability and more than $75 \%$ report that the condition has impacted their employment and career opportunities [19].

The theme is constant: pwMS struggle to continue working and a higher percentage are unemployed than in the rest of the population. The reasons for this are multifactorial and discussed in depth in our review paper [20]. With regards to work pwMS could be categorized into four different groups: newly diagnosed (information seeking), working yet worried (symptom management, support, advice, disengagement from work), Work crisis (disciplinary hearing, redundancy, relapse) or not working yet want to (advice, support, regaining employment). This is shown clearly in the British Society for Rehabilitation Medicine Recommendations [21] (BSRM) in Figure 1 below. 


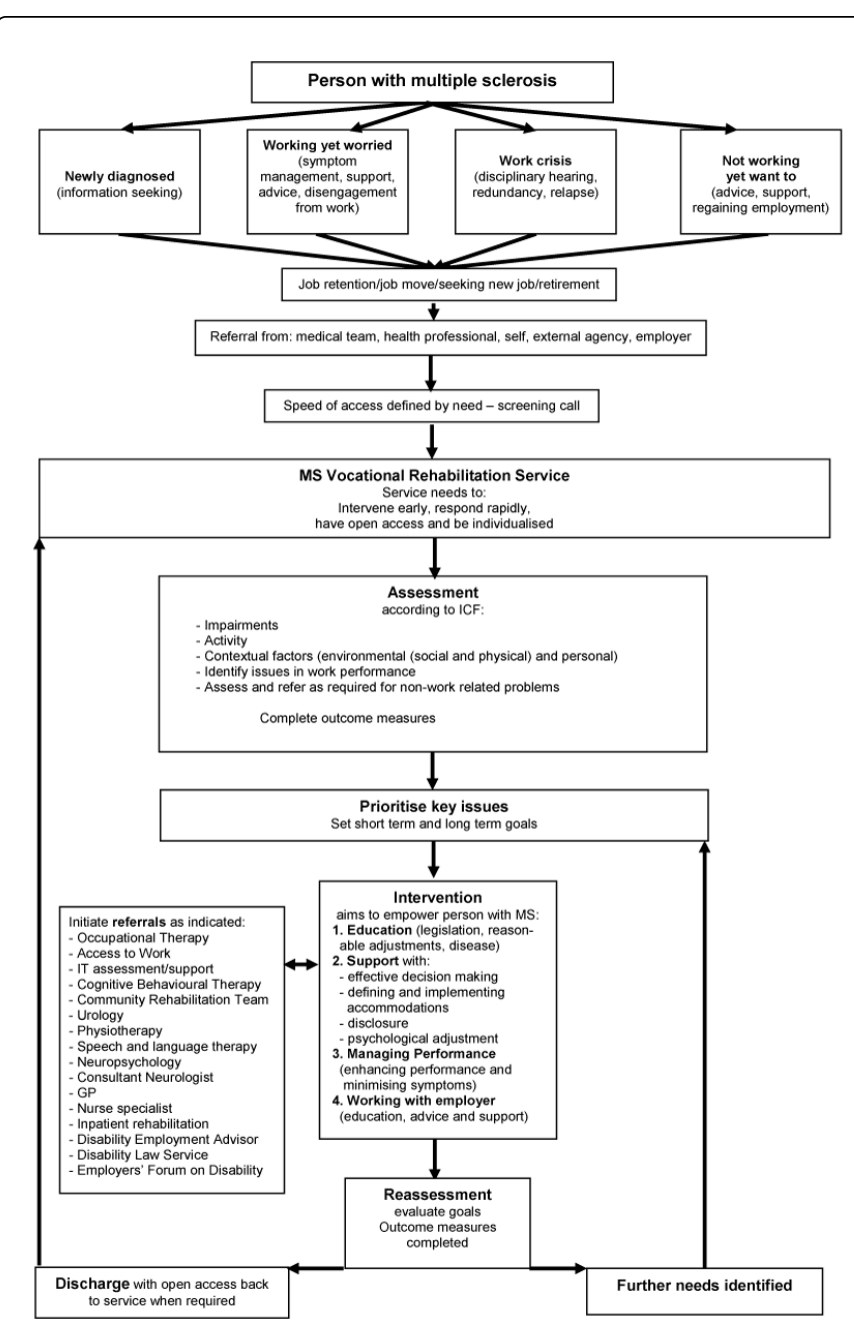

Figure 1: Signs of a person with Multiple Sclerosis

There is potential need to intervene at any of these stages but this depends on the individual and their work context. Research to date suggests that early intervention is essential in any VR intervention that aims to keep a person with MS in work20. A study by Kirk-Brown [22] showed that early disclosure in work is beneficial. However the literature rarely defines what is meant by 'early intervention'. One study reported that pwMS may not take advantage of job retention schemes until a crisis develops or their job becomes unstable [23]. The term 'work instability' emerged from the work of Tennant et al [24,25] and is defined as a state in which the consequences of a mis-match between an individual's functional (and cognitive) abilities and the demands of their job can threaten continuing employment if not resolved. It is at this stage that professional intervention is thought to be of most benefit [26]. However, pwMS fitting this description and potentially needing access to VR do not always identify themselves as having work difficulties. They may have hidden and or undisclosed disabilities such as mild cognitive or visual impairment, low mood or fatigue, which may negatively impact on their own or team work performance, yet they don't acknowledge these at work [11].

In a randomised control trial (RCT) to evaluate an early intervention VR service for pwMS in our centre [27], 'early' was defined as within a year of diagnosis. In this paper we explore what is meant by 'early intervention' through the use of two case studies purposely selected from participants randomised to receive early VR as part of this trial. We discuss the value of early intervention and illustrate its impact in these two cases.

\section{Methods}

\section{Procedure}

The randomised controlled trial to evaluate an early intervention VR intervention for pwMS commenced in 2009. Patients seen in the MS nurse diagnostic or relapse clinics at the National Hospital for Neurology and Neurosurgery (NHNN), who fulfilled the inclusion criteria (in employment and within one year of diagnosis), were asked to participate in a study about work. Consenting patients were randomised to receive either 'early vocational rehabilitation intervention' delivered by an occupational therapist (OTVR) or 'usual care' (UC). UC participants received information about sources of employment related help available for people with disabilities. The OTVR group received up to nine hours of intervention. It was anticipated at the study outset that the OTVR would consist of (i) an initial assessment, ii) discussion about disclosure and provision of information (iii) a work place visit and (iv) a debriefing session to summarize the meetings and to discuss options for the individual and their employer. Ethical approval for the study was obtained from the joint research ethics committee of the NHNN and the Institute of Neurology (UCL).

The two cases presented in this paper were purposively selected from participants randomized to receive OTVR. They were chosen by the treating occupational therapist in discussion with the study lead because they were considered representative [28,29] of pwMS randomised to OTVR and thought to typify people who present at MS clinics within a year of diagnosis with no significant symptoms and report 'no problems at work'. They were chosen to illustrate the impact of MS on different work roles.

One was chosen as representative of predominantly desk based professional /managerial role with a lot of autonomy and another who was employed in a manual role with less autonomy and greater potential for impact on work colleagues. These cases were chosen to illustrate the importance and nature of early VR intervention.

\section{Results}

The case studies are structured using the International Classification of Functioning and Disability in Health (ICF) [30], and followed the four stages of intervention described in the BSRM Recommendations [31]. The process is illustrated in Figure 1 in the section headed 'Intervention: Education, Support, Managing performance and Working with employer'. The intervention is underpinned by an initial assessment in which key areas are prioritised and short term and long term goals agreed. Once intervention is complete, the goals are evaluated and either further needs identified or discharge agreed.

\section{Case study: Annabelle}

\section{Assessment}

\section{2/05/09 - Meeting in Outpatients}


Background information: Annabelle, aged [32,33], was diagnosed with relapsing remitting MS thirteen months prior to entering the study. At initial assessment she reported no specific work issues. Prior to her involvement in the study she had received no information about work and MS nor sought any support following diagnosis.

Current job: Annabelle was a nurse at a specialist hospital where she had worked for five years. She was 10 years post qualification and worked in acute care where she did 10 hour shifts, four days a week in the post surgery recovery room. She reported enjoying her work. Current role: Annabelle's main responsibilities were caring for patients when they came out of theatre; observing their immediate recovery, liaising with family and accompanying patients back to the ward once stable.

Work environment: Annabelle worked on a busy, brightly lit, often hot, noisy hospital ward. She spent most of her time on her feet with little time sitting down.

Travel to work: Annabelle had a ten minute walk from her home to work. Employer support: Annabelle had not disclosed her MS to anyone at work.

Social Situation: Annabelle lived in subsidized nursing accommodation. Her family was not local and Annabelle sometimes travelled 4 hours by train to get home for the weekend. Annabelle reported a quiet social life, which involved seeing friends, shopping and attending church.

Psychological wellbeing: Annabelle reported finding her initial diagnosis very hard however she reported feeling stronger now.

Symptoms: At the initial assessment Annabelle reported fatigue, pins and needles in part of her face, leg spasms at night, which prevented her from sleeping; numbness in her left arm on waking, which took up to two hours to settle. Annabelle reported that her symptoms had worsened in the heat the previous summer and she was anxious that this might impact on her work performance in the summer ahead.

Main issue: Annabelle reported that she wanted to be honest at work and disclose that she had MS; she reported not knowing how to do so.

Summary: When asked by the MS clinic nurses if she had any problems at work she had clearly stated not. It was evident from the initial assessment that Annabelle was anxious about disclosure and that fatigue was having a marked impact on work; with increased anxiety about symptoms worsening in the heat and the impact this may have on her work performance in summer months.

\section{Prioritising key issues}

In discussion with Annabelle the following areas were identified as a priority.

Advice about legal rights and further discussion about disclosure at work

A fatigue management programme to focus specifically on the impact of fatigue at work in the context of Annabelle's role and her ability to do this.

\section{Intervention}

10/06/09 session 1
Disclosure and legal rights: Annabelle's legal rights and options around disclosure at work were discussed. It was agreed that Annabelle would disclose to her Human Resources (HR) department and then following their recommendations, decide when to tell her line manager. For now Annabelle did not intend to inform her colleagues. We discussed Annabelle's legal rights under the Equality Act [31] (formerly Disability Discrimination Act [32]). Annabelle recognised that she was protected by the law and had the right to ask for reasonable adjustments at work.

Fatigue: Fatigue was a problem that impacted on Annabelle's working day. A fatigue management session was planned for the next appointment and Annabelle was asked to keep a fatigue diary. Annabelle reported spasms at night, which were affecting her sleep. This had a profound impact on her fatigue levels at work.

\section{The plan following session 1 was for:}

Annabelle to write down what she might say in disclosing her MS to HR

Annabelle to keep a fatigue diary for one week

The occupational therapist to refer to the MS specialist nurses regarding the night spasms and sleep disturbance.

\section{July/august - relapse off work 5 weeks}

\section{8/09/09 Session 2}

\section{Disclosure:}

We used a role play to practice disclosure. Annabelle practiced what she thought she would say to her HR colleague. She felt this increased her confidence and believed she could now be more assertive when she disclosed. We used the 'MS and Work' booklet [33] to see if this might help in facilitating an understanding of MS with her line manager.

Fatigue: We worked on fatigue management [34]; discussing the theories behind MS fatigue with an aim of increasing Annabelle's understanding of fatigue. We reviewed her fatigue dairy and used it to suggest fatigue management strategies for use at work. The strategies discussed were:

to obtain a portable fan for use on the ward as heat exacerbated her fatigue

to incorporate rest periods in her shifts to request work place accommodations in the form of changes in working patterns and working hours. Annabelle to ask not to be rotad four days in a row

Condition Management: We discussed the timing of Annabelle's neurology appointments. Annabelle reported that she always seeks appointments outside of work hours, which often means she waiting longer for an appointment, which fits with her rota. We discussed whether work could consider it a reasonable adjustment to allow Annabelle leave from work to attend the appointments in work time, particularly as the clinic is a short walk away from her workplace.

We also discussed a 'Workplace Adjustment Agreement [35]' to clearly outline her current symptoms and any adjustments needed to plus protect herself should her line manager change (common on her ward).

\section{The plan following session 2:}

Annabelle booked an appointment to meet with HR and her line manager. She planned to take the 'MS and work' [33] booklet with her. 


\section{$15 / 09 / 09$ session 3}

\section{Work place visit:}

Annabelle called and requested that I attend the planned disclosure meeting with HR as she was feeling anxious. HR agreed Annabelle could bring the VROT with her to the meeting. In this meeting Annabelle did most of the talking. She looked to me for assurance as she shared her diagnosis and questions about MS, which Annabelle could not answer (e.g., Will work make her condition worse? What is Annabelle's prognosis) were taken by me. Discussions were had about the proposed reasonable adjustments and the Workplace Adjustment Agreement 35 introduced for future use. The HR representative took the 'MS and Work'33 book to read as she reported knowing very little about the condition.

Annabelle reported afterwards that she felt she had managed the meeting well and was well prepared, although she valued the presence of the VROT. She felt she could manage future meetings alone.

\section{Reassessment}

\section{7/12/09 Outpatient review}

At a final meeting Annabelle reported that she had chosen to disclose to the Sister and the ward team. This enabled the sister to explain the differential treatment Annabelle sometimes received (e.g. no four days in a row on shift). Annabelle felt relieved to have done this and although difficult initially, everyone was 'just getting on now'. Annabelle reported still not having a fan, despite constantly asking but there was no explanation as to why it had not yet arrived. She reported feeling much more confident and able to advocate for herself. She had completed the Workplace Adjustment Agreement [35] with her line manager and felt it acted as a safety net. Annabelle was receiving medication for her spasms, which had improved her sleep, and therefore felt less fatigued.

Outcome: No further input was considered necessary but Annabelle was given an open access to VROT.

\section{Case study: Erica}

\section{Assessment}

\section{3/03/09 - Meeting in Outpatients}

Background Information: Erica, aged 54, was diagnosed with relapsing remitting MS six months prior to entering the study. She was diagnosed during a three month period of sickness absenceand had been back at work full time for three months. At the start of the session Erica reported no specific work issues. Prior to her involvement in the study she had not received any information about work and MS nor sought any support following diagnosis.

Current job: Erica was one of eight directors in a large Government agency. Her direct line manager was the Chief Executive Officer (CEO). Erica worked Monday - Wednesday in the office, then Thursday and Friday at home. She usually worked $9-5 \mathrm{pm}$; and ate a working lunch at her desk.

Current role: Erica managed a team of 27 people including her Personal Assistant (PA) with whom she worked closely. Her role was to look continuously at the agency's strategy and spend. Her job was primarily desk-based. She worked at her computer in her own spacious office and attended both internal and external meetings.
Work Environment: Ergonomically she was well set up with a supportive chair, footrest and well positioned computer. She saw an Occupational Health physician when she returned to work. This was standard process at the Government Agency where she was employed for people off work for more than eight weeks. The $\mathrm{OH}$ physician recommended voice activated software because she found typing difficult due to reduced sensation and stiffness in her hands. This was awaited. When Erica worked at home she did not have the same set up and reported using a laptop and often sitting on her bed or the sofa to work.

Travel to work: Erica reported that she drove to work in her automatic car and parked directly behind the building where she worked. The journey took $30-40$ minutes. She used to travel by public transport but this was time consuming and exhausted her, so she had started driving since her diagnosis. She said she needed to be careful and acknowledge when her energy levels were low so that she felt alert and safe to drive home. She was very strict about leaving work by $5 \mathrm{pm}$.

Employer support: When Erica was diagnosed she told the CEO via phone. She had some anxiety that the CEO might have told the other senior managers which she was not happy about. She was unsure whether to discuss this concern with the CEO.

Social Situation: Erica lived with her partner in their own house in the city. Erica had socialised less since being diagnosed, as she was so tired in the evenings.

Psychological wellbeing: Erica reported that she was still in shock following her diagnosis.

Symptoms: At the initial assessment Erica reported fatigue as her main symptom. She said she did not sleep well anymore, often struggling to go to sleep (she described a vicious cycle of getting into bed, trying to go to sleep, becoming aware of tingling in her legs, which made her anxious, then worrying about her condition, which prevented her from sleeping) or she waking in the night then struggling to go back to sleep. She also reported experiencing numbness and tingling in her hands, legs and feet; and stiffness in her hands.

Summary: it was evident that Erica was feeling uncertain about work and the impact that MS may have, she was unsure about managing relationships at work and disclosing her MS to her team. She reported feeling the impact of fatigue but was unsure what to do about it and she felt it was something she just had to get on with. It was unclear whether her home office set up was appropriately.

\section{Prioritising key issues}

In discussion with Erica the following areas were identified as a priority.

to discuss Erica's legal rights and further explore disclosure both with the CEO and the team

to review Erica's ergonomic set up at home

to review Erica's IT needs

to start a fatigue management programme; looking more specifically at the impact of fatigue at work in the context of Erica's occupational performance .

\section{Intervention}

\section{9/06/09 session 1}


Page 5 of 7

Legal rights and disclosure: Erica was aware of her legal protection under the Equality Act. We discussed disclosure; Erica reported having mixed feelings and some days she wanted to disclose to everyone and other days to no one. I advised her to ask herself 'why does she want to disclose?' and reminded her that she did not have to disclose to anyone. We talked about how it may be useful to disclose to her PA, although she is new in post and therefore Erica does not feel she has the right relationship with her yet. We discussed how Erica needed to ask her CEO, who else she had told about Erica's condition, as Erica was anxious that other people should not know.

Ergonomic set up: Erica has a good ergonomic set up at work in her work office, although she has a small computer screen and would benefit from a larger screen. She needs a similar office set up at home. Erica would benefit from either a desk top computer or a separate keyboard and screen at a desk with appropriate seating, to ensure good posture and positioning at home as well as work. We discussed using the Access to Work ${ }^{*}$ scheme for a home office assessment. ( ${ }^{*}$ Access to Work can help people with disabilities who wish to take up employment, or who are in work and experience difficulties related to their disability. It can also help employers who wish to recruit or retain people with disabilities in employment. https://www.gov.uk/access-towork/overview )

IT needs: Erica would benefit from voice activated software and this has been ordered for her through her employers' occupational health service.

Fatigue: Erica found her level of fatigue increased during the day. Erica reported finding her fatigue frustrating. She felt that all she could manage was her work at the expense of everything else. We discussed how she might use the Access to Work scheme to fund a taxi to work to remove the energy drain of driving.

Managing work relationships: Erica reported her relationship with her CEO was good. However she was keen that when they met they did not always have to discuss her MS. We discussed the 'workplace adjustment agreement' and how this might facilitate future discussions and put some structure in place for Erica and her CEO.

The plan following session 1 was for:

Erica to consider disclosing to her PA;

Erica to speak with her CEO and remind her that diagnosis is confidential and that she must seek Erica's permission to disclose;

Erica to keep a fatigue diary for one week;

Erica to refer herself to Access to Work; and

Erica to identify the need for a larger computer screen at her desk either through occupational health or when Access to Work come to assess her.

\section{0/07/09 Session2:}

\section{We discussed:}

Fatigue management: we reviewed Erica's fatigue diary and looked at where fatigue was affecting her day. This included driving to work and the Erica said she found the strip lighting in her office very stark and wondered if that made her eyes tired. We discussed some of the theories behind MS fatigue. We identified some simple strategies for Erica to use. The immediate things that needed to be addressed were: office lighting at work Erica. Erica reported that the 'Access to Work' taxi was being set up.

\section{Disclosure:}

Erica decided to disclose to her PA as she felt it would be helpful to have support at work

\section{Plan following session 2:}

For Erica to;

disclose to her PA and speak to the CEO about MS,

Make a referral to Access to Work so that they can assess Erica's work environment (including the lighting) and her home office set up

\section{Set up taxi to work service through Access to Work}

\section{1/02/10 Final session:}

Erica was using Access to Work taxis, which helped in diminishing her fatigue levels. Access to Work had also assessed Erica's home and office making recommendations for the provision of office furniture and a large computer screen Erica; posturally this made working at home easier and reduced her fatigue. Erica had met with her CEO who stated she had told the other directors. Erica had told the CEO she felt this was inappropriate and was mustering up the courage to discuss her condition with all the Directors. She had disclosed her diagnosis to her PA and instructed her PA to manage her diary by spreading her workload and building in rest periods, including a lunch break. She reported this was having a positive impact on her working day and increasing her levels of productivity. Fatigue remained an issue but was more manageable and having less impact on her evenings.

\section{Discussion}

This study presents two different case examples of people working with MS in the first year following diagnosisBoth patients were randomized to receive an early occupational therapy VR intervention as part of a trial. Neither reported work difficultiesat an MS clinic. However through the initial assessment completed by the treating occupational therapist it was evident that there were condition- related difficulties, which were impacting on work. These were addressed in the VROT intervention that followed.

The process described in the case studies maps onto the VR process presented in the BRSM guidelines21. In both cases the pwMS presented in clinic in the 'newly diagnosed' category however following an initial assessment, were classified as 'Working yet Worried'. In both cases, when issues were identified and prioritized there were a number of similarities. Both had anxieties about work, including the impact of fatigue. Both were experiencing

confusion or uncertainty around disclosure. Both were uncertain about MS management in the future and its potential to impact on work. In both cases the occupational therapy response to referrals was quick and each intervention was individualized.

One concern illustrated by these cases is that neither participant reported any work related issues at the point of referral. During the initial assessment in which specific questions are asked about work and people were encouraged to reflect on their employment, it became evident quickly that MS was impacting on work either directly through symptoms or as a result of non-disclosure or great uncertainty following disclosure. Both patients described in these case examples were anxious and uncertain about their future. The key features of the intervention were around education about early symptom management especially fatigue, legal rights, preparation for and support with disclosure, and education and support around accessing external input such as the Access to Work scheme. This process of educating and supporting people in the early stages of MS fits well 
with Ross'38 belief that an 'essential element of the VR process is to help the person to come to terms with their disability or health condition and to understand and manage the ways in which it impacts on their occupational performance'.

Clinical implications

These two cases highlight significant challenges for clinical practice. The principal challenge is the timing of the intervention - ensuring we are seeing the right people and asking the right questions, at the right time. Firstly how can we ensure that pwMS are asked about work in a way that will highlight the problems they faced? What training or skills are needed on the part of the healthcare team to ask these questions or prompt early OT referral? What service developments may be needed to facilitate this?

Occupational therapists working with pwMS should reflect on whether they are asking clients about work in a way that encourages them to reflect on their condition and its impact in the work place. They should explore whether pwMS have made their own work place accommodations without really thinking of them as accommodations (for examples Erica not using the tube any more, ensuring she finishes work early). These two case studies illustrate that it may be possible for a period following diagnosis to deny the impact of MS at work and that during this time, some people attempt to hide early symptoms such as fatigue and bladder weakness until a minor problem becomes a crisis. This could be one reason why pwMS exit the workforce prematurely. If better educated and supported early on in the work journey such premature exits maybe avoided.

It would seem important that health professionals working with pwMS should consider whether they are equipped to deal with the questions that follow when asking pwMSabout work38. Health care professionals may benefit from further training in the area of vocational rehabilitation.

These two cases illustrate the benefits of an early VROT intervention within a year of MS diagnosisfor the people who received them. Unlike neurological conditions thatimpact suddenly such as traumatic brain injury or stroke and where questions about the ability to return to work are more obvious, in pwMS the insidious creep of symptoms into all aspects of daily life over time means they may be struggling at work long before they realise they have a problem. Health care professionals working in MS clinics might also assume that pwMS will self-identify if they need support or that the impact of MS on a person's job is not their role. Supporting people with long-term conditions to remain in work is the job of health6. Vocational rehabilitation should be seen as an integral part of the rehabilitation process and not a bolt on8;26 and needs to begin at the point of diagnosis with a health professional experienced in VR exploring the true impact of the condition on a person's work ability and role. In our case examples, it was only by asking the right questions at the right time that deep anxieties about the MS and how it was impacting on work were revealed.

The question remains if we equip pwMS early in their disease journey, with information about their legal rights and support them with disclosure and fatigue management strategies before any significant work problems arise, will this reduce time to withdrawal from work and better prepare them for the journey ahead? It is this question which future research should explore.

\section{Acknowledgements}

This research was made possible through a grant from the UK OT research Foundation (UKOTRF) at the College of Occupational
Therapy. Thank you to Dr Afsane Riazi for her time in reviewing this paper.

\section{References}

1. McCrone P, Heslin M, Knapp M, Bull P, Thompson A (2008) Multiple sclerosis in the UK: service use, costs, quality of life and disability. Pharmacoeconomics 26: 847-860.

2. Atlas multiple sclerosis resources in the world (2008). World Health Organisation. Ref Type: Report

3. Compston A, Coles A (2008) Multiple sclerosis. Lancet 372: 1502-1517.

4. College of Occupational Therapists, National Social Inclusion Programme. Work Matters: Vocational navigation for occupational therapy staff. 30-11-2007. London, College of Occupational Therapists and the National Social Inclusion Programme. Ref Type: Pamphlet

5. Sayce L (2011) Getting in, staying in, and getting on: disability employment support fit for the future. Department of Work and Pensions. Ref Type: Report

6. Black C (2008) Working for a healthier tomorrow. London, TSO. Ref Type: Report

7. Waddell G, Burton AK (2006) Is work good for your health and wellbeing? 2006. Department of Work and Pensions. Ref Type: Report

8. Eva G, Playford ED, Sach T, Barton G, Risebro H, Radford K et al. (2012) Thinking positively about work: Delivering work support and vocational rehabilitation for people with cancer; Evaluation of the National Cancer Survivorship Initiative (NCSI) Work and Finance Workstream, Vocational Rehabilitation Project. Macmillan Cancer Support. Ref Type: Report

9. Waddell G, Burton AK, Kendall N (2008). Vocational Rehabilitation: What works, for whom, and when? London, The Stationary Office. Ref Type: Report

10. Frank AO, Thurgood J (2006) Vocational rehabilitation in the UK: Opportunities for health care professionals. International Journal of Therapy and Rehabilitation 13: 126-134.

11. Playford ED, Radford K, Burton C, Gibson A, Jellie B, et al. (2011). Mapping vocational rehabilitation services for people with long term neurological conditions: Summary report. 2011. Department of Health.

12. Wilson PM (2005) Long-term conditions: making sense of the current policy agenda. Br J Community Nurs 10: 544-545, 548-52.

13. Brown PF, Tulloch AD, Mackenzie C, Owen GS, Szmukler G, et al. (2013) Assessments of mental capacity in psychiatric inpatients: a retrospective cohort study. BMC Psychiatry 13: 115.

14. Multiple Sclerosis International Federation (2010). MSIF survey on Employment and MS.

15. Compston A, Coles A (2002) Multiple sclerosis. Lancet 359: 1221-1231.

16. O'Connor RJ, Cano SJ, Ramió i Torrentà L, Thompson AJ, Playford ED (2005) Factors influencing work retention for people with multiple sclerosis: cross-sectional studies using qualitative and quantitative methods. J Neurol 252: 892-896.

17. Gordon PA, Lewis MD, Wong D (1994) Multiple sclerosis: Strategies for rehabilitation counsellors. Journal of Rehabilitation (July/August/ September): $34-38$.

18. Ford DV, Jones KH, Middleton RM, Lockhart-Jones H, Maramba ID, et al. (2012) The feasibility of collecting information from people with Multiple Sclerosis for the UK MS Register via a web portal: characterising a cohort of people with MS. BMC Med Inform Decis Mak 12: 73.

19. Bevan S, Zheltoukova K, McGee R, Blazey L (2011) Ready to Work? Meeting the employment and career aspirations of people with Multiple Sclerosis. The Work Foundation.

20. Sweetland J, Howse E, Playford ED (2012) A systematic review of research undertaken in vocational rehabilitation for people with multiple sclerosis. Disabil Rehabil 34: 2031-2038.

21. British Society for Rehabilitation Medicine, Jobcentre Plus (2010). Vocational assessment and rehabilitation for people with long-term neurological conditions: Recommendations for best practice. 
Citation: Joanna S, Playford DE, Radford KA (2014) What Is 'Early Intervention' for Work Related Difficulties for People with Multiple Sclerosis? A Case Study Report. J Neurol Neurophysiol 5: 252. doi:10.4172/2155-9562.1000252

Page 7 of 7

22. Kirk-Brown A, Van Dijk P, Simmons R, Bourne M, Cooper B (2013) Disclosure of diagnosis of multiple sclerosis in the workplace positively affects employment status and job tenure. Mult Scler .

23. Rumrill PD, Roessler RT, Vierstra C, Hennessey M, Staples L (2004). Workplace barriers and job satisfaction among employed people with multiple sclerosis: An empirical rational for early intervention. Journal of Vocational Rehabilitation 20: 177-183.

24. Gilworth G, Chamberlain MA, Harvey A, Woodhouse A, Smith J, et al. (2003) Development of a work instability scale for rheumatoid arthritis. Arthritis Rheum 49: 349-354.

25. McFadden E, Horton MC, Ford HL, Gilworth G, McFadden M, et al (2012) Screening for the risk of job loss in multiple sclerosis (MS): development of an MS-specific Work Instability Scale (MS-WIS). Mult Scler 18: 862-870.

26. Chamberlain MA (2007) Work, disability and rehabilitation: making the best job of it. Clin Med 7: 603-606.

27. Playford ED, Sweetland J (2014) To evaluate an early intervention model of occupational rehabilitation for people with multiple sclerosis. College of Occupational Therapy. 31-3-0014.

28. Bowling A (2005) Research methods in health: Investigating health and health services. 2 ed. Open University Press.

29. Neale P, Thapa S, Boyce C (2006) Preparing a case study: a guide for designing and conducting a case study for evaluation input. Pathfinder
International. Pathfinder international tool series. Monitoing and evaluation.

30. World Health Organisation (2006) International classification of functioning, disability and health. 2006.

31. HMSO (2010) The Equality Act. 2010. Ref Type: Bill/Resolution

32. HMSO (1995) The Disability Discrimination Act. Ref Type: Bill/ Resolution

33. Finn L, Sweetland J, Playford ED (2010). Work and MS: for employees and employers. 4th Ed. MS Society. Ref Type: Pamphlet

34. Harrison S (2007) Fatigue management for people with multiple sclerosis. 2 ed. London: Bristish Association of Occupational Therapists.

35. Sweetland J, Playford ED (2010) 'Working yet Worried' A toolkit of information and resources for pwMS who are in employment. MS Society. Ref Type: Pamphlet.

36. Hobart J, Lamping D, Fitzpatrick R, Riazi A, Thompson A (2001) The Multiple Sclerosis Impact Scale (MSIS-29): a new patient-based outcome measure. Brain 124: 962-973.

37. McGuigan C, Hutchinson M (2004) The multiple sclerosis impact scale (MSIS-29) is a reliable and sensitive measure. J Neurol Neurosurg Psychiatry 75: 266-269.

38. Ross J (2007). Occupational therapy and vocational rehabilitation. John Wiley and sons ltd. 